\title{
The Effect of Dietary Pattern and Body Mass Index on the Academic Performance of In-school Adolescents
}

\author{
Seyi Elizabeth Ogunsile ${ }^{1}$ \\ ${ }^{1}$ Department of Human Kinetics and Health Education, Ekiti State University, Ado-Ekiti, Nigeria \\ Correspondence: Seyi Elizabeth Ogunsile, Department of Human Kinetics and Health Education, Ekiti State \\ University, PMB 5363, Ado-Ekiti, Nigeria. Tel: 234-802-787-4680. E-mail: Se.ogunsile@yahoo.com
}

Received: July 16, 2012 Accepted: July 26, 2012 Online Published: September 26, 2012

doi:10.5539/ies.v5n6p65 URL: http://dx.doi.org/10.5539/ies.v5n6p65

\begin{abstract}
The main objective of this study was to determine the effects of dietary pattern and body mass index on the academic performance of in-school adolescents in Ekiti State. One hundred and twenty eight students (10-19 years) selected from three senior secondary schools in Ekiti State Nigeria, formed the participants for this study. Questionnaire was the instrument for data collection and the data were subjected to descriptive and inferential statistics (bivariate Pearson correlation analysis and linear regression) using Spss version 12 at 0.05 level of significance. Findings of this study showed that of all the adolescents, only $16.4 \%, 14.1 \%, 7.0 \%, 16.4 \%$ and $10.2 \%$ followed a healthy dietary pattern of regular intake of breakfast, three square meals, milk, fruits and vegetables respectively. $50 \%, 38.3 \%$ and $45.3 \%$ followed an unhealthy dietary pattern of regular intake of sweets, chewing gum and soft drinks. With regards to body mass index and academic performance, less than $40 \%$ of the respondents were of normal weight and only half of the respondents had good academic performance. Body mass index, breakfast consumption, eating three square meals and regular intake of fruits and vegetables all had significant effects $(\mathrm{P}<0.05)$ on the academic performance of adolescents. Also, there was a significant joint effect of body mass index and healthy dietary pattern on the academic performance of these adolescents. Parents and school authorities should make all efforts to ensure healthy dietary pattern among adolescents so as to enhance their academic performance.
\end{abstract}

Keywords: in-school adolescent, dietary pattern, body mass index, academic performance

\section{Introduction}

Adolescence is the most critical period human beings experience in the course of existence. How well individuals navigate this turbulent period and become successful adults depends on the extent to which they get the necessary support from those ahead. Adolescence is a transition period between childhood and adulthood. It is a developmental period which involves tremendous growth both physically, psychologically and cognitively (McDaniel, 2012). It is also a period when many adolescents are in school engaging in various forms of academic activities which impose challenges on their cognitive ability. For these adolescents to get on well with their academics, their intellectual ability needs to be enhanced.

To enhance the cognitive as well as the physical development of adolescents, the right quantity and quality of nourishment is needed. Adolescence is a period of rapid development which requires increase ingestion of essential nutrients from foods to catch up with the developmental needs. Failure to fulfil this demand often results in varying degrees of malnutrition which have implication both on the health and academic performance of adolescents. Lynn (2011) submitted that children who do not have enough quality food to eat can suffer physically more frequently than children who ate the proper amount of food. Reporting a previous study, Lynn reported that malnourished children in the study reported cases of "stomach aches, headaches" and colds more frequently than their well nourished counterparts. Lynn concluded that if a child is hungry at school, and experiences the physical symptoms of hunger, he will have a harder time concentrating on his studies.

To get the right kind of nourishment, adolescents need to adopt a healthy eating pattern on a daily basis. Nutrition experts have suggested that adolescents eat a variety of foods, have regular intake of breakfast and three square meals, eat plenty grains, low fat diet, moderate sugar and salts, calcium and iron rich diet and plenty of fruits and vegetables and balance the food they eat with physical activity so as to meet up with their growing body's requirements. It is stated in Keepkidshealthy (2012) that ensuring proper nutrition in adolescence can also 
prevent many medical problems, including becoming overweight, developing weak bones, and developing diabetes.

Adolescents' food choices, nutrient intake and overall nutritional status have been reported to be affected by factors such as the quest for independence and acceptance by peers, increased mobility, greater time spent at school and/or work activities, and preoccupation with self-image (Jenkins \&Horner 2005). In addition, studies have shown that certain socio-demographic factors such as age, sex, ethnicity, geographical location, educational status of household heads and socio-economic factors often influence dietary behaviour developed by adolescents (Godwin, Knol, Eddy,Fitzhugh \&Donahue, 2006).Similarly, the review of McClain, Chappius, Nguyen-Rodriguez, Yaroch and Spruijt-Metz (2009) revealed some psychosocial correlates of healthy eating such as knowledge, intention to eat healthy, perceived modelling and norms.

The effect of diet on academic performance has been documented. Many authors have spoken in favour of good nourishment for better academic performance. Lynn (2011) stated that a well-rounded diet is necessary for a child's physical and academic growth. On the other hand, Grantham-McGregor (1995) reported that early childhood malnutrition such as stunting, underweight and anaemia which often occur as a result of insufficient daily consumption of foods have been found to be negatively associated with cognitive development and academic attainment later in life. Bounds, Nettles and Johnson (2009) citing Meyers, Simpson and Weitman (1991), submitted that under-nutrition as a result of poor diet quality, is associated with decreased school attendance, attention and decreased academic performance as well as more health problems. It can therefore be concluded that there is need to provide learners with quality diet in order improve their cognitive functioning and academic performance.

Breakfast is the first meal of the day. Evidence abounds on the role of breakfast in academic performance. Lynn (2011) citing Rampersaud, Pereira, Girard, Adams and Metzl (2005) opined based on evidence that breakfast consumption improves well-being and cognitive function related to memory, test grades, and school attendance. Lack of breakfast has been associated with feelings of headache, restlessness, being irritable, and inability to concentrate well on studies and poor academic performance. Eating breakfast has been associated with higher energy levels, better learning ability, better attention span, higher grades in math, and significantly fewer behavioural and emotional problems (Kleinman, 1998). Apart from daily breakfast consumption, having regular three main meals of the day has also been reported to have positive correlation with academic performance. Kim, Frongillo, Han (2003) reported a positive association between consumption of regular meals and academic performance. Another important dietary pattern consistent with academic performance is fruit intake. Florence, Asbridge and Vengellers (2008); MacLellan, Taylor and Wood (2008), Abudayya, Shi and Holmoo-Ottesen (2011) all reported that increased in fruit and vegetable intake and increase in dietary quality were significantly associated with academic performance.

With regards to body mass index, Kenneth (2004) cited by Oketayo, Ojo, Inyang, Adenodi, Akinluyi and Akinnubi (2010) stated that high levels of fitness at school is significantly associated with high level of cardiovascular fitness, better school attendance, fewer disciplinary incidents and better academic performance. Hoffman Policastro Quick and Lee (2006) also reported a negative significant correlation between body weight and academic performance indicating that obesity may have adverse effect on academic performance. Oketayo et al (2010) reported that for overweight and obese subjects, a negative correlation was observed between academic performance and body and body weight respectively.

There is a kind of agreement in the findings of all the literature cited. It can thus be concluded that ensuring a healthy dietary pattern and normal weight are essential in enhancing the academic performance of adolescents.

\section{Problem Statement}

The present and future implication of academic performance of learners at all levels has made it a public health concern. Poor diet quality and overall health status of adolescents are among the prominent factors implicated for poor academic performance among adolescents. In Nigeria (Ekiti State inclusive), poor health status and low level of academic performance have been reported among in-school adolescents. A report of the Federal ministry of health showed that almost a third of young people in both primary and secondary schools in Nigeria are undernourished while $9 \%$ are over nourished. With regards to academic performance, Yusuf and Adigun (2010) reported low level of academic performance among in-school adolescents in Ekiti State. The rationale for this study was based on the fact that while much work had been done on the influence of factors such as school type and location, parental involvement, family structure and sex on academic performance of in- school adolescents in Ekiti State, the researcher could not lay hold on any study that considered the effects of dietary pattern and 
body mass index on academic performance among in-school adolescents in Ekiti State. This study thus seeks to bridge this gap.

\section{Objective of the Study}

The objective of this study was to determine the effect of dietary pattern and the corresponding body mass index on the academic performance of in-school adolescents in Ekiti state, Nigeria.

\section{Hypotheses}

The following hypotheses were tested in this study

Ho1. There will be no significant effect of healthy dietary pattern on academic performance of in-school adolescents.

Ho2. There will be no significant effect of unhealthy dietary pattern on academic performance.

Ho3.There will be no significant effect of body mass index on academic performance of in-school adolescents.

Ho4. There will be no significant joint effect of healthy dietary pattern and body mass index on academic performance of in-school adolescents.

\section{Method and Procedure}

\subsection{Design}

The study adopted the Ex-post facto research design in order to determine the effects of dietary pattern and body mass index on academic performance of in-school adolescents in Ekiti State, Nigeria.

\subsection{Participants}

A total number of 128 secondary school students between the ages of 10 and 19 years selected from three senior secondary schools located within Ekiti State participated in this study. Participants were selected from science, social science, arts and commercial classes. One of the major limitations for this study is small sample size. Most of the schools that suppose to constitute the study site did not give their consent for data collection. The three schools involved in this study represented those whose authorities granted the researcher permission for data collection. This study was carried out in February 2012.

\subsection{Data Collection}

Questionnaire was the instrument for data collection. The instrument elicited responses on participants' demographic attributes (age \& gender), dietary pattern, body mass index and academic performance. The instrument on dietary pattern had a response format of: 'never' (1), '1-2 days week' (2), '3-4 days a week' (3) '5-6 days a week' (4) and 'everyday' (5). Dietary pattern variables were classified into: 'healthy dietary pattern' (milk intake, fruit and vegetable intake, breakfast consumption and consumption of three square meals) and 'unhealthy dietary pattern' (sweet, chewing gums and soft drink intake). The dietary behaviour questionnaire (DBQ) had eight items with a reliability coefficient of 0.754 . Cronbach alpha was used to determine the reliability coefficient of the instrument.

The body mass index of participants was calculated using the formula: weight $(\mathrm{kg}) / \mathrm{height}\left(\mathrm{m}^{2}\right)$. Weight of the participants was obtained using the bathroom scale which is an already validated instrument while the height was measured using a tape measure. To ensure that the bathroom scale measured what it was suppose to measure, the researcher ensures that the starting point of the instrument before any weighing was zero. Body mass index of participants was then classified using WHO (2006) classification: < 18.5 underweight (1), 18.5-24.9 'normal' (2), 25-29.9 'overweight' (3) and > 40 'obesity' (4).

To determine the academic performance, examination scores in five major subjects in participants' area of discipline (science, social science, arts and commercial) were obtained for three consecutive terms and the average of these scores for each participant was obtained. The average mark for each student was then graded. Those who had average mark below 40 were graded 'poor'(1), 40-49 'fair' (2) 50-59 'above average'(3), 60-69 'good' (4), 70 and above 'excellent'(5).

After the coding, the data were subjected to Pearson correlation analysis and linear regression to determine the effect of dietary pattern and body mass index on adolescents' academic performance using SPSS version 12 at 0.05 level of significance. 


\section{Analysis and Interpretation of Data}

Demographic attributes of respondents

Data analysis revealed that majority (53.1\%) of the respondents are female, 50.8\% were between $10-14$ years only $37.5 \%$ were of normal weight and half of the respondents had $60 \%$ and above in academic performance. With regards to pattern of dietary intake, $7.0 \%$ took milk at least once a day, $16.4 \%$ reported daily breakfast intake, $14.1 \%$ reported daily intake of three square meals, $16.4 \%$ eat fruit daily, $10.2 \%$ eat vegetables daily, half of the respondents reported daily intake of sweets, $38.3 \%$ eat chewing gum daily and $45.3 \%$ reported daily intake of soft drinks.

Table 1. Body mass index, dietary pattern and academic performance of adolescents

\begin{tabular}{ll}
\hline Variable & $\begin{array}{c}\text { Academic performance } \\
(\mathrm{r})\end{array}$ \\
\hline BMI & $-.309^{*}$ \\
Breakfast consumption & $.194^{*}$ \\
Three square meals & $.226^{*}$ \\
Milk intake & .055 \\
Fruit intake & $195^{*}$ \\
Vegetable intake & .115 \\
Soft drink intake & -.157 \\
Chewing gum intake & .020 \\
Sweet intake & -.035 \\
\hline
\end{tabular}

Table 1 above shows that body mass index, daily breakfast consumption and fruit intake had significant correlation with academic performance of in-school adolescents. Body mass index had a negative correlation with academic performance indicating that the lesser the body mass index the better the academic performance of these adolescents. Also, healthy dietary pattern (breakfast consumption, three square meal intake, milk intake, fruit and vegetable intake) had positive correlation with the academic performance of adolescents indicating that healthy dietary pattern was associated with better academic performance of adolescents.

Hypothesis 1: There will be no significant effect of healthy dietary pattern on academic performance of in-school adolescents.

Table 2. Effect of healthy dietary pattern on academic performance

\begin{tabular}{llclll}
\hline Model & Sum of Squares & df & Mean Square & F & P-value \\
\hline Regression & 15.052 & 5 & 3.010 & 2.853 & .018 \\
Residual & 120.273 & 114 & 1.055 & & \\
Total & 135.253 & 119 & & & \\
\hline
\end{tabular}

Adjusted $\mathrm{R}^{2} .072$

Table 2 above shows that healthy dietary pattern has a significant effect on academic performance $(\mathrm{P}<0.05)$ hence hypothesis 1 is rejected. The independent variables (i.e breakfast consumption, fruit and vegetable intake, milk intake and consumption of three square meals made $.072(7.2 \%)$ contributions on the academic performance of in-school adolescents.

Hypothesis 2: Ho2. There will be no significant effect of unhealthy dietary pattern on academic performance. 
Table 3. Effect of unhealthy dietary pattern on academic performance

\begin{tabular}{lcclll}
\hline Model & Sum of Squares & df & Mean Square & F & P-value \\
\hline Regression & 4.830 & 3 & 1.610 & 1.457 & .230 \\
Residual & 133.698 & 121 & 1.105 & & \\
Total & 138.528 & 124 & & & \\
\hline
\end{tabular}

Adjusted $\mathrm{R}^{2} .011$

Table 3 above shows that unhealthy dietary behaviour (intake of sweets chewing gum and soft drink) does not have significant effect on academic performance of in-school adolescents $(\mathrm{P}>0.05)$ hence hypothesis 2 is accepted. The findings however revealed that unhealthy dietary behaviour among these adolescents made .011 $(1.1 \%)$ contributions on the academic performance of these adolescents.

Hypothesis 3: There will be no significant effect of body mass index on academic performance of in-school adolescents.

Table 4. Effect of body mass index on academic performance

\begin{tabular}{lcclll}
\hline Model & Sum of Squares & df & Mean Square & F & P-value \\
\hline Regression & 13.449 & 1 & 13.449 & 12.904 & .000 \\
Residual & 127.156 & 122 & 1.042 & & \\
Total & 140.605 & 123 & & & \\
\hline
\end{tabular}

Adjusted $\mathrm{R}^{2} .088$

Table 3 above shows that body mass index has significant effect on academic performance of adolescents $(\mathrm{P}<0.05)$ hence hypothesis 3 is rejected. The percentage contribution of body mass index on academic performance was $8.8 \%$.

Hypothesis 4: There will be no significant joint effect of healthy dietary pattern and body mass index on academic performance of in-school adolescents.

Table 5. Joint effect of healthy dietary pattern and body mass index on academic performance

\begin{tabular}{llclll}
\hline Model & Sum of Squares & df & Mean Square & F & P-value \\
\hline Regression & 25.845 & 9 & 4.307 & 4.624 & .000 \\
Residual & 102.463 & 110 & .931 & & \\
Total & 128.308 & 116 & & & \\
\hline
\end{tabular}

Adjusted $\mathrm{R}^{2} .158$

Table 4 above shows a statistically significant joint effect of dietary pattern and body mass index on academic performance of in-school adolescents $(\mathrm{P}<0.05)$ hence hypothesis 4 was rejected. The percentage contribution of body mass index and healthy dietary pattern on academic performance of in-school adolescents was $15.8 \%$.

\section{Discussion}

The findings of this study that healthy dietary pattern had significant positive influence on academic performance of adolescents, confirms the findings of previous researches like that of Kim, Frongillo and Han (2003); Florence, Asbridge and Vengellers (2008) who reported a positive association between consumption of regular meals, increased fruit and vegetable intake and increased dietary quality on academic performance. Garret (2012) also reported that students who normally receive less than 50 percent of the recommended daily caloric intake were more likely to have poor attendance in school, lower grades and exhibit more behavioural problems than those not at nutritional risk. 
The positive significant association between breakfast consumption is also consistent with previous findings. Rampersaud et al 2005 cited by Lynn (2011) reported a positive association between breakfast and academic performance. Breakfast is the first meal of the day which supplies the needed glucose for brain functioning. Lack of breakfast consumption has been associated with feelings of headache, restlessness, being irritable and inability to concentrate well on studies and hence poor academic performance. Eating breakfast on the other hand has been associated with higher energy levels and better learning ability better attention span, higher grades in math, and significantly fewer behavioural and emotional problems (Kleinman, 1998). It is however unfortunate to note that while majority of these in-school adolescents studied engaged in regular intake of sweets, chewing gum and soft drinks which are of low nutritive value, only very few of them engaged in a healthy dietary pattern on a regular basis. As a matter of fact, only $16.4 \%$ of these adolescents reported a regular breakfast intake. Quick intervention is therefore needed to facilitate the adoption of healthy dietary pattern among in-school adolescents in Ekiti State.

The positive significant association observed between having three square meals and academic performance, is consistent with previous findings. Kim et al (2003) reported a positive association between regular meal intake and academic performance among adolescents. To obtain the necessary nourishment by adolescents having healthy meals at the three main periods of the day is essential. Anything below or above this standard can result in under-nutrition or over-nutrition and both are not consistent with good health status and academic performance of adolescents. Like it was reported for breakfast intake, only $14.6 \%$ of the in-school adolescents that were studied reported regular intake of three square meals which may likely be the reason why not more than half of the respondents could attain good academic performance.

The findings of this study that fruit intake had a significant positive correlation with academic performance is also consistent with previous findings. Florence et al (2008); MacLellan, Taylor and Wood (2008) both reported a better academic performance among adolescents with increased fruit and vegetable intake. Also, Abudayya, Shi and Holmoo-Ottesen (2011) reported that even after controlling for socio-economic status, fruit intake was still positively significantly correlated with academic performance among adolescents. Fruits are good sources of micronutrients which may play significant role in the cognitive development of adolescents.

The findings of this study that body mass index has a significant negative correlation with academic performance, is an indication that the lower the body mass index, the better the academic performance. This study is in favour of normal body mass index rather than overweight or obesity. This finding is consistent with findings of authors like Policastro, Lee and Soo-Kyang (2006) ; Oketayo, Ojo, Inyang, Adenodi, Akinluyi and Akinnubi (2010); Taras and Potts-Datema (2005). These all reported a negative significant correlation between body mass index and academic performance which indicate that overweight and obesity may have adverse effects on academic performance.

The findings that body mass index and healthy dietary pattern when put together have significant joint effect on academic performance, was expected. A healthy diet characterised by increased fruit and vegetable intake, regular meals, breakfast consumption and milk intake for adolescents, often results in normal healthy weight, improved cognition, improved health condition, better school attendance and better academic performance.

The findings of this study that dietary pattern and body mass index had overall percentage contribution of $17.1 \%$ on the academic performance of these adolescents, is suggestive that there is more to academic performance than dietary pattern and body mass index among these adolescents. Other factors not controlled for in this study such as students' motivation, health conditions of adolescents; teachers' competency among others must have also had their contributions on the academic performance of these adolescents. Influence of factors such as teachers' competence, students' motivation, parental involvement and political instability on the academic performance is therefore recommended for future research.

\section{Conclusion}

Based on the findings of this study, it can be concluded that healthy dietary pattern and normal body weight are positive contributors to academic performance. Maintaining a healthy diet often results in healthy weight, good physical, psychological and cognitive development and a better academic performance of learners. Learners who are well nourished are better able to cope with the rigour of academics thus translating to a better academic performance.

\section{Recommendations}

Based on the findings of this study, it is recommended that:

1) Healthy dietary pattern which consists of regular nutritious breakfast consumption, daily intake of three square meals and liberal fruit and vegetable intake should be encouraged among learners at all levels. 
2) Parents and teachers should serve as role models for children and adolescents in matters relating to healthy feedings. Also, school meals should be such that provide students with healthy food items.

3) Unhealthy foods like sweets, chewing gums and soft drinks should be discouraged among learners.

4) Parents should ensure healthy feeding among their adolescents

5) Schools should make provisions for only healthy meals, snacks and drinks in their meal centres in order to facilitate healthy eating among adolescents.

6) Regular physical activities to ensure normal weight should be encouraged among adolescents.

\section{Acknowledgement}

The author wishes to express sincere gratitude to the management, staff and students of schools from where the data for this study was collected. Also special thanks go to Miss Abimbola Oluwafunmilayo, Miss Falowo Morenike and Mr Fasusi for their contributions in making this study a success.

\section{References}

Abudayya, A., Shi, Z., Abed, Y., \& Holmboe-Ottesen. (2011). Diet, nutritional status and school performance among adolescents in Gaza Strip. Eastern Mediterranean Health Journal, 17(3), 218-225.

Bounds, W., Nettles, F. M., \& Johnson, J. T. (2009). Recess before lunch programs in elementary schools: perceptions and practices of school professionals. Retrieved from http://www.schoolnutrition.org/Content.aspx?id=12502 (August 03, 2012)

Florence, M. D., Asbridge, M., \& Veugellers, P. J. (2008). Diet quality and academic performance. Journal of School Health, 78(4), 209-215. http://dx.doi.org/ 10.1111/j.1746-1561.2008.00288.x

Garret, M. (2012). Diet and school performance. Retrieved from http://www.livestrong.com/article/361515-diet-school-performance/ (July 16, 2012)

Godwin, D., Knol, K., Eddy, J. M., Fitzhugh, E., \& Donahue, R. (2006). Socio-demographic correlates of overall dietary intake of U.S. adolescents. Nutrition Research, 26, 105-110.

Grantham-McGregor, S. (1995). A review of studies of the effect of severe malnutrition on mental development. Journal of Nutrition, 125 (suppl.), 2233S-2238S.

Hoffman, D. J., Policastro, P., Quick, V., \& Lee, S. K. (2006). Changes in body weight and fat mass of men and women in the first year of college: A study of the "freshman 15". Journal of American College of Health, 55(1), 41-45.

Jenkins, S., \& Horner, S. D. (2005). Barriers that influence eating behaviours in adolescents. Journal of Paediatric Nursing, 20, 258-267. http://dx.doi.org/doi:10.1016/j.pedn.2005.02.014

$\begin{array}{llll}\text { Keepkidshealthy. } & \text { (2012). } & \text { Nutrition. } & \text { Retrieved from }\end{array}$ http://www.keepkidshealthy.com/adolescent/adolescentnutrition.html (July 16, 2012)

Kim, H.Y., Frongillo, E.A., Han, S. S., Oh, S.Y., Kim, W.K., Jang, Y. A., ... Kim, S. H. (2003). Academic performance of Korean children is associated with dietary behaviours and physical status. Asian Pacific Journal of Clinical Nutrition, 12(2), 186-192.

Kleinman, R. (1998). New Harvard research shows school breakfast program may improve children's behaviour and performance. Retrieved from http://www.kidsource.com/kidsource/content4/breakfast.html (July 17, 2012)

Lynn, D. (2011). Diet, Breakfast, \& Academic Performance in Children. Retrieved from http:/www.livestrong.com/article/262517-diet-breakfast-academic-performance-in- children/ (July 13, 2012)

MacLellan D, Taylor J., \& Wood, K. (2008). Food intake and academic performance among adolescents. Canadian Journal of Dietetic Practice and Research, 69(3), 141-144.

McClain, A. D., Chappuis, C., Nguyen-Rodriguez, S. T. Yaroch, A. L., \& Spruijt-Metz, D. (2009). Psychosocial correlates of eating behaviour in children and adolescents: a review. International Journal of Behavioural Nutrition and Physical Activity, 6(54). http://dx.doi.org/doi:10.1186/1479-5868-6-54

McDaniel, R. (2012). Physical and cognitive development of adolescents. Retrieved from http://www.ehow.com/about_6668490_physical-cognitive-development-adolescents.html (July 15, 2012) 
Oketayo, O. O., Ojo, J.O., Inyang, E. P., Adewodi, R. A., Akinluyi, F. O., \& Akinnubi, R. T. (2010). The effect of body weight, body fat and body mass index on adolescents' academic performance. Nature and Science, 8(6), 36-42.

Taras, H. (2005). Nutrition and student performance at school. Journal of School Health, 75(6), $199-213$. http://dx.org/doi: 10.1111/j.1746-1561.2005.00025.x

Taras, H., \& Potts-Datema, W. (2005). Obesity and students' performance at school. Journal of School Health, 75, 291-295. http://dx.org/doi: 10.1111/j.1746-1561.2005.00040.x

WHO. (2006). BMI Classification. $\quad$ Retrieved from http://apps.who.int/bmi/index.jsp?introPage=intro_3.html11/07/2012 (July13, 2012)

Yusuf, M. A., \& Adigun, J. T. (2010). Influence of school, Sex, location and type on students' academic performance. International Journal of Education and Science, 2(2), 81-85. 